\title{
Sensoriamento remoto aplicado em área de caatinga como subsídios para conservação da biodiversidade
}

É notável que o modelo de desenvolvimento econômico atual não vem mostrando resultados satisfatórios quanto à proteção e cuidado com a natureza, pelo contrário, os impactos ambientais e sociais têm aumentado significativamente, alterando os ecossistemas e colocando em risco a biodiversidade brasileira, especificamente, no bioma Caatinga, objeto de estudo desta pesquisa. A Caatinga é um bioma rico em biodiversidade, contudo, vem sendo marcado pela crescente pressão e exploração dos recursos naturais. $O$ uso insustentável tem causado a degradação de áreas e favorecendo o processo de desertificação, que já se mostra intenso na região semiárida. Nesse contexto, diante da relevância da conservação da biodiversidade deste bioma, especificamente a flora apícola, este trabalho objetivou identificou as classes de uso do solo e a cobertura vegetal através dos Índices de Vegetação por Diferença Normalizada-NDVI Temperatura da Superfície Terrestre-TST e Índice de Vegetação Abastecida de Água-WSVI, numa área de Caatinga no Sertão Paraibano. Para isso utilizou-se das técnicas de geoprocessamento e do sensoriamento remoto para a análise desses índices, que mostraram uma variabilidade da vegetação e áreas de solo exposto. Os índices TST e o WSVI evidenciaram temperaturas amenas e maior umidade nas áreas com presença de vegetação, respectivamente.

Palavras-chave: Índices de vegetação; Sustentabilidade; Sertão Paraibano

\section{Remote sensing distribution in caatinga area as subsidies for biodiversity conservation}

\begin{abstract}
It is remarkable that the current economic development model has not shown satisfactory results regarding the protection and care with nature, on the contrary, the environmental and social impacts have increased significantly, changing ecosystems and endangering Brazilian biodiversity, specifically in the Caatinga biome, the object of this research. The Caatinga is a biome rich in biodiversity, however, it has been marked by increasing pressure and exploitation of natura resources. The unsustainable use has caused the degradation of areas and favoring the process of desertification, which is already intense in the semi-arid region. In this context, given the importance of the biodiversity conservation of this biome, specifically the apiculture flora, this work aimed to identify land use classes and plant cover through the Vegetation by Normalized Difference Vegetation Index-NDVI, land surface temperature-LST and water supply begetation index-WSVI in an area of Caatinga in the Paraiba Hinterland. For this purpose, geoprocessing and remote sensing techniques were used to analyze these indices, which showed variability in vegetation and exposed soil areas. The TST and WSVI indexes showed mild temperatures and higher humidity in areas with vegetation, respectively.
\end{abstract}

Keywords: Vegetation indices; Sustainability; Sertão Paraibano.

Topic: Conservação da Biodiversidade

Reviewed anonymously in the process of blind peer.
Received: 08/04/2021

Approved: 07/05/2021
Micaela Silva Coelho (iD

Universidade Federal de Campina Grande, Brasil

http://lattes.cnpq.br/1752230516197243

http://orcid.org/0000-0001-5982-5304

micaela.agro@hotmail.com

José Diogenes Alves Pereira (ib

Universidade Federal de Campina Grande, Brasil

http://lattes.cnpq.br/0794148901792036

http://orcid.org/0000-0002-8160-4126

diogenes 753@hotmail.com

Mycarla Míria Araújo de Lucena (iD

Universidade Federal de Campina Grande, Brasil

http://lattes.cnpq.br/3657048424265608

http://orcid.org/0000-0002-3093-7625

mycarlalucena@gmail.com

\author{
Rosilene Agra da Silva \\ Universidade Federal de Campina Grande, Brasil \\ http://lattes.cnpq.br/6371251034099783 \\ http://orcid.org/0000-0001-9232-7403 \\ rosileneagra@hotmail.com \\ Iaponira Sales de Oliveira \\ Pontifícia Universidade Católica do Paraná, Brasil \\ http://lattes.cnpq.br/8305961486407142 \\ iapobio@hotmail.com \\ Janny Eyry Farias Souza de Araújo \\ Universidade Federal de Campina Grande, Brasil \\ http://lattes.cnpq.br/0903869008687655 \\ jacyfarias@gmail.com
}

Referencing this:

COELHO, M. S.; PEREIRA, J. D. A.; LUCENA, M. M. A.; SILVA, R. A. S.; OLIVEIRA, I. S.; ARAÚJO, J. E. F. S.. Sustentabilidade agrícola e saúde do solo. Revista Ibero Americana de Ciências Ambientais, v.12, n.5, p.159-166, 2021. DOI: http://doi.org/10.6008/CBPC21796858.2021 .005 .0014 


\section{INTRODUÇÃO}

O Brasil é considerado por contemplar uma rica biodiversidade, dentre os 17 países que abrigam 70\% da riqueza de espécies do planeta, o Brasil é o mais megadiverso (SCARANO et al., 2016). Para estes autores essa biodiversidade é a garantia da oferta de serviços ecossistêmicos que são vitais para a sobrevivência e o bem-estar humano. Mittermeier et al. (2011) demonstra a preocupação pela conservação da biodiversidade mundial, pois dentre as várias consequências da perda da biodiversidade, está incluso a deterioração do capital natural da Terra, bem como a redução da resiliência dos ecossistemas e das comunidades humanas que dependem deles.

Nesse cenário, encontra-se o Semiárido brasileiro, que está localizado no nordeste do país, que apresenta uma área territorial de $980.133,07 \mathrm{~km}^{2}$, abrangendo 1.135 municípios, destes, 1.050 estão situados em oito estados do Nordeste; e uma população estimada em 22.598.318 habitantes, correspondendo a $11,85 \%$ do país (INSA, 2014). Nessa região, localiza-se o Domínio das Caatingas, considerado rico em biodiversidade e espécies endêmicas (CASTELLETTI et al., 2003), porém ainda permanece sendo pouco estudado e protegido em comparação com as florestas tropicais e savanas adjacentes (ALBUQUERQUE et al., 2012; KILL et al., 2019).

Contudo, a caatinga passa por um extenso processo de devastação ambiental provocado pelo uso insustentável dos seus recursos naturais, associados à existência de grandes áreas com solos de baixa fertilidade e à ocorrência de secas periódicas, tornando-a uma das áreas mais degradadas do Brasil, com vários núcleos de desertificação (TROVÃO et al., 2009; CASTRO et al., 2011).

Esta também é uma realidade do Estado da Paraíba, Sá et al. (2003), destacam essa região com a presença dos mais graves problemas gerados pela desertificação no Brasil, sendo a causa primária as alterações na paisagem do bioma Caatinga ao longo do século. Conforme Tavares (2018) é notório que com a utilização de práticas inadequadas como a exemplo das queimadas vem acarreando uma série de problemas voltados para a extinção de espécies vegetais e animais do bioma Caatinga no sertão paraibano.

Com as técnicas de sensoriamento remoto, tornam-se possíveis a quantificação e qualificação de vários parâmetros biofísicos da vegetação, como cobertura do solo, atividade fotossintética e a caracterização e monitoramento de áreas com vegetação, entre outros. Normalmente, estas estimativas são efetuadas com a utilização dos chamados Índices de Vegetação (IVs) e outras variáveis extraídas de imagens de sensoriamento remoto, apresentando a grande vantagem de proporcionar a acessibilidade de informações em locais remotos e de difícil acesso, além de menos onerosos, em termos de trabalhos de campo, quando comparados aos métodos tradicionais (FERRAZ, et al., 2013).

Contudo, este trabalho enfatiza a importância da conservação da biodiversidade da flora apícola frente ao panorama da utilização destes recursos para os mais diversos fins, seja na pesquisa e desenvolvimento de outros produtos, de forma a sintetizar um resultado que possa trazer uma perspectiva sobre a importância da flora apícola brasileira e no desenvolvimento sustentável da região semiárida. Além disso, estes resultados visam contribuir com os Objetivos do Desenvolvimento Sustentável - ODS, especificamente, o ODS 15 - vida terrestre "proteger, recuperar e promover o uso sustentável dos 
ecossistemas terrestres e gerir de forma sustentável as florestas, combater a desertificação, deter e reverter à degradação da terra e deter a perda de biodiversidade" (ONU, 2015).

Nesse contexto, diante da relevância da conservação da biodiversidade da Caatinga, aliada à praticidade que as técnicas de sensoriamento remoto favorecem, este estudo identificou as classes de uso do solo e a cobertura vegetal através dos Índices de Vegetação por Diferença Normalizada-NDVI, Temperatura da Superfície Terrestre- TST e Índice de Vegetação Abastecida de Água (WSVI-Water Supplying Vegetation Index).

\section{METODOLOGIA}

\section{Área de estudo}

O Córrego das Gadelhas está situado no município de Pombal, no Estado da Paraíba, mais precisamente no sertão paraibano, possui aproximadamente 31,57ha de área (Figura 01), a mesma detém características do Bioma Caatinga da região Nordeste.

O município de Pombal está inserido na Depressão Sertaneja Setentrional, conforme as classificações em ecorregiões de Caatinga segundo Velloso et al. (2002), apresentando clima semiárido e quente, e ocorre o período chuvoso geralmente entre outubro a abril. A precipitação apresenta-se de baixa pluviosidade, sendo anualmente em torno de $500 \mathrm{~mm}$ a $800 \mathrm{~mm}$. Exibe um relevo predominantemente suave-ondulado, com elevações residuais disseminadas na paisagem. Os solos são rasos, pedregosos, de origem cristalina e fertilidade média alta, mas muito suscetíveis à erosão. É composto por uma vegetação arbustiva e arbórea (VELLOSO et al., 2002). Segundo o IBGE (1992) as caatingas têm sido classificadas como savana-estépica, hierarquizadas em diversas tipologias.

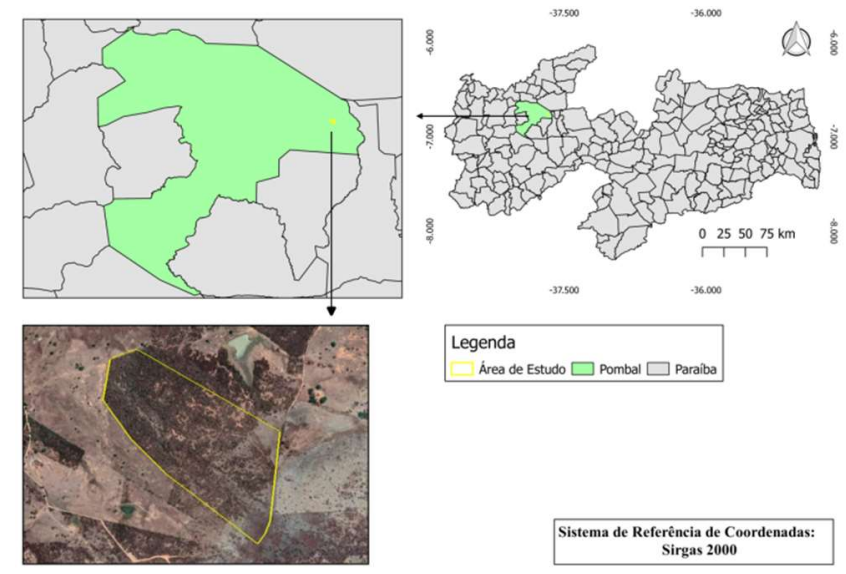

Figura 1: Mapa de localização da área de estudo. Fonte: IBGE (2019); GOOGLE EARTH PRO (2020).

\section{Procedimentos metodológicos}

Esta área de estudo foi analisada por um conjunto de ações em campo e por práticas de sensoriamento remoto e geoprocessamento de imagens de satélite, a qual está sendo utilizado imagens do software Google Earth, dados vetoriais cedidos pelo IBGE (2019), o software livre Qgis 2.18 e uma imagem de satélite LandSant 8 cedida pelo Serviço Geológico Norte Americano (USGS) captada às 12h:41m:46s do 
dia 17 de outubro de 2020 .

Esta imagem inicialmente passou pelo processamento digital de correção atmosférica, dada a utilização do complemento do Qgis - SCP - Semi Automatic Classification Plugin (PEREIRA, 2020), que converteu a imagem bruta em subprodutos de melhor qualidade.

Posteriormente foi realizado o cálculo do Índice de Vegetação por Diferença Normalizada-NDVI criado por Rouse (1973), que expressa a presença de vegetação em uma área a uma escala superior a zero tendendo a +1 em valores, e de forma oposta a ausência de vegetação em uma área é dada por valores em escala inferiores a zero se aproximando de -1 . Obtido esta informação foi gerado um mapa de NDVI que aponta a presença de vegetação a nível municipal em Pombal, com o foco no Corrégo das Gadelhas, para assim visualizar áreas que detém uma maior concentração de vegetação. Na equação 1 tem-se o pressuposto do NDVI.

$$
\mathrm{NDVI}=\frac{(N I R-R)}{(N I R+R)}
$$

R: Banda espectral referente ao infravermelho próximo; $\mathrm{R}$ : Banda espectral referente ao vermelho.

Em seguida foi estimada a temperatura da superfície terrestre (TST), sendo assim gerado um mapa que seguiu a premissa da visualização da área de estudo, bem como das áreas de entorno a nível municipal, a qual as temperaturas estimadas são justas e dependentes da presença e ausência de vegetação, apontando assim possíveis subáreas passivas de antropização ou do oposto dentro da área foco do estudo. Seguem na equação 2 as variáveis para se alcançar tais informações (PEREIRA, 2020):

$$
T S T=\frac{T b}{\ln (\mathrm{E}) \times\left(0,00115 \frac{T b}{1,4388}\right)+1}
$$

Tb: Temperatura de brilho no topo da atmosfera; E: Emissividade da superfície terrestre do NDVI

O Índice de Vegetação Abastecida de Água-WSVI, determina segundo Alshaikh (2015) o quanto a vegetação se encontra abastecida de água, por uma variação em escala de -4 a +4 , na forma que valores obtidos inferiores a zero apontam a inexistência de vegetação com armazenamento de água, e para valores superiores a zero tendenciando a +4 tem-se vegetação que detém umidade. Neste entendimento foi gerado um mapa de WSVI datado com a mesma estrutura vistas no de NDVI e TST, para expressar quais áreas em cenário municipal e em específico no Córrego das Gadelhas detém vegetação com umidades expressivas passivas de serem áreas mais densas de vegetação. Na equação 3 têm-se as variáveis que alcançam o WSVI.

$$
W S V I=\frac{N D V I}{T S T}
$$

NDVI: Índice de Vegetação por diferença Normalizada; TST: Temperatura da Superfície Terrestre. 


\section{RESULTADOS E DISCUSSÃO}

Ao analisar a área de estudo quanto ao Índice de Vegetação por Diferença Normalizada (Normalized Difference Vegetation Index- NDVI), detém uma variabilidade que se encontra nas cores vermelhas, laranja e amarelo claro, a qual essas cores estão pertencentes em todo município, mas diferindo de zonas com maior densidade de vegetação encontradas fora da nossa área de estudo (Figura 02).

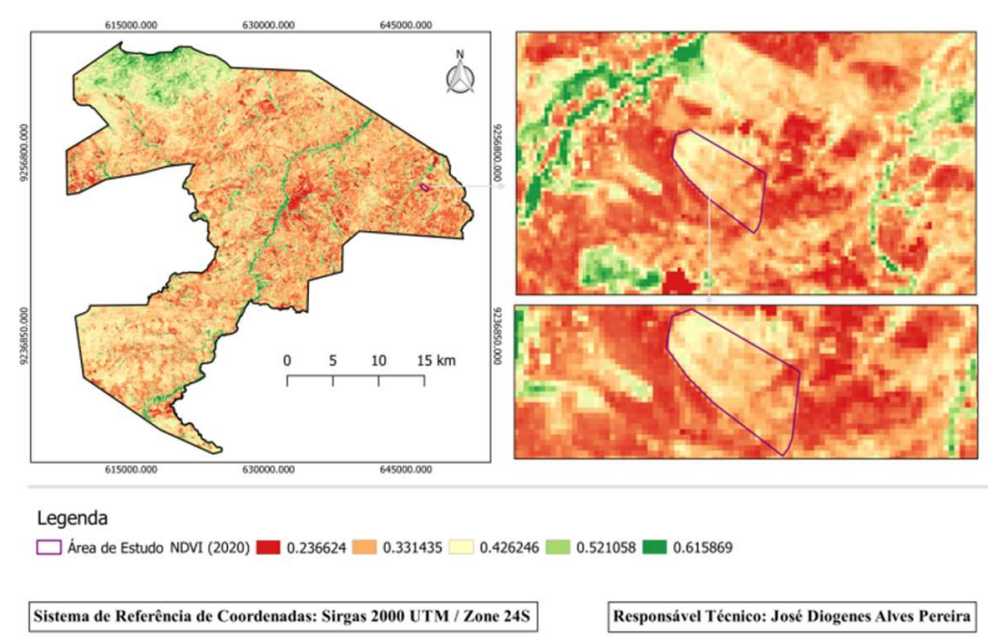

Figura 2: Mapa de NDVI do Córrego das Gadelhas. Fonte: IBGE (2019); USGS (2020).

No polígono que delimita o Córrego das Gadelhas é possível observar uma zona sugestiva na cor vermelha com valores de 0.236624 , que in loco foi constatado que é uma área antropizada (Figura 03). Quanto à densidade de vegetação dentro do polígono é visto que as cores que mais predominam são as cores laranja e amarelo claro, com valores de 0.331435 e 0.42646 respectivamente, apontando uma preservação da vegetação se comparada às áreas de entorno do polígono. Em estudo realizado por Lourenço, Ramos e Costa (2017), os resultados foram semelhantes quanto a variabilidade na espacialização da vegetação, dada a algum agente e por consequência se apresentaram áreas preservadas e áreas não vegetadas, onde as áreas não vegetadas do estudo dos autores se deu por ações antrópicas, tal qual a área vermelha no córrego das Gadelhas.

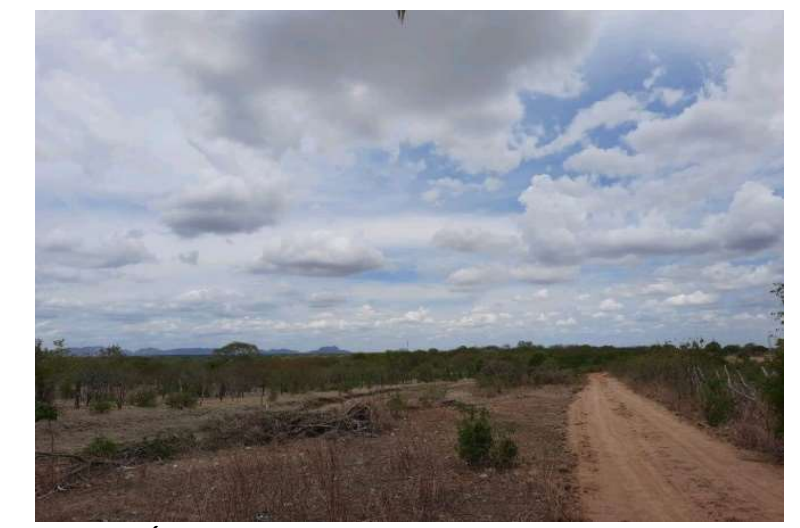

Figura 3: Área de solo exposto do Córrego das Gadelhas.

Quanto as estimativas de temperatura de superfície terrestre à nível municipal, observou-se uma variabilidade de $33,62^{\circ} \mathrm{C}$ à $46,78^{\circ} \mathrm{C}$, de forma que no Córrego das Gadelhas teve uma concentração de 
temperatura de $40,20^{\circ} \mathrm{C}$, correspondendo à temperatura máxima registrada (Figura 4). Nota-se que as localidades mais vegetadas proporcionaram uma atenuação da temperatura ficando na faixa de $40,20^{\circ} \mathrm{C}$ à $43,49^{\circ} \mathrm{C}$, e a zona antropizada constatada in loco deteve a maior temperatura registrada na área de estudo devido ao solo exposto, acarretando assim uma maior concentração de calor, diferentemente das áreas vegetadas.

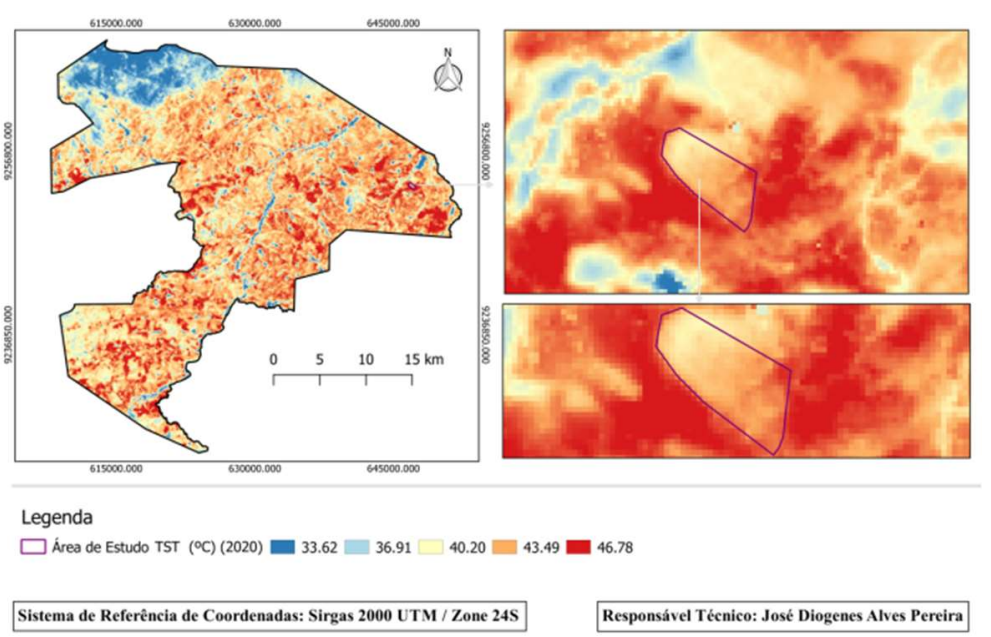

Figura 4: Mapa de TST do Córrego das Gadelhas Fonte: IBGE (2019); USGS (2020).

De forma similar ao estudo de Pereira et al. (2020) realizado no Sertão Paraibano, analisaram as variabilidades de temperaturas em áreas distintas onde a área vegetada e área degradada ou desmatada tiveram temperaturas similares ao presente estudo deste projeto. Ou seja, ambas as áreas de estudos apresentaram temperaturas elevadas para áreas de solo exposto devido ações antrópicas.

Em consonância com o NDVI e TST, obteve-se o WSVI para a área de estudo apontando as áreas vegetadas úmidas vistas pelas cores laranja e amarelo, com valores de 0.008215 e 0.011207 respectivamente, bem como a área de solo exposto pela cor vermelha, visto que tem a ausência de vegetação e consequentemente, deteve a menor umidade na área (Figura 5).

O estudo de Pereira et al. (2021) no município de Sousa no interior da Paraíba, apresentou resultados de WSVI semelhantes ao estudo no córrego dos Gadelhas, onde áreas vegetadas expressaram mais umidade, e as áreas de solo exposto a ausência de umidade dada a inexistência ou baixa existência de vegetação.

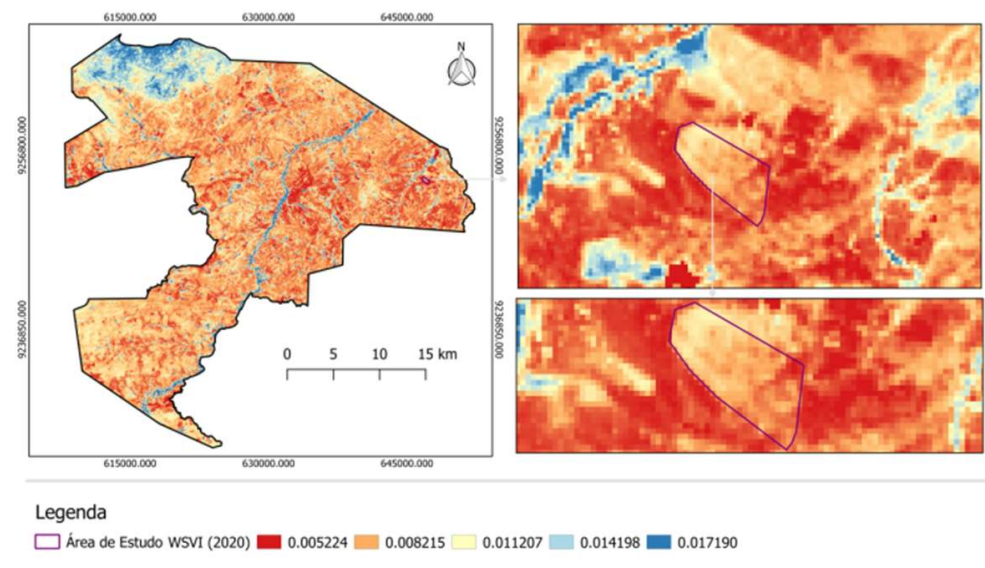

Sistema de Referência de Coordenadas: Sirgas 2000 UTM / Zone 24S $\quad$ Responsável Técnico: José Diogenes Alves Pereira

Figura 5: Mapa de WSVI do Córrego das Gadelhas. Fonte: IBGE (2019); USGS (2020). 
Deste modo, os resultados apresentados pelas imagens possibilitaram ter uma análise do uso e ocupação do Terra da área de estudo, proporcionando a indicação para as coletas e identificação da flora apícola, que é um dos objetivos específicos deste projeto, bem como ao final avaliar a sua influência na riqueza da flora apícola. Além disso, este mapeamento contribui com os projetos que venham a favorecer o desenvolvimento local sustentável desta área de caatinga, principalmente, como instrumento de planejamento e gestão da apicultura, endossando assim a conservação da biodiversidade da Caatinga, essencialmente as abelhas. Esses resultados contribuirão para os Objetivos do Desenvolvimento Sustentável-ODS, especialmente, o ODS 15- vida terrestre, que visa proteger, recuperar e promover o uso sustentável dos ecossistemas terrestres, bem como combater a desertificação e reverter às áreas degradadas e deter a perda da biodiversidade.

\section{CONCLUSÕES}

Considerando os dados obtidos pelo NDVI foi perceptível que a área detém uma variabilidade de vegetação, assim como, uma área sugestiva com a ausência delas, estas por sua vez, comprovadas in loco que são áreas de solo exposto decorrente de ações antrópicas. Quanto ao TST, foi perceptível que ele foi consonante com o mapa de vegetação devido à vegetação presente na área e a variabilidade se comportarem de formas atenuadoras de temperatura, bem como a área de solo exposto deteve a maior temperatura dentro da área de estudo devido ao solo exposto por naturalidade ser uma área que é superaquecida.

E quanto ao WSVI, foi perceptível que nas áreas mais densas de vegetação também foram as áreas dentro da localidade que se detiveram maior umidade na vegetação. Visto todos os dados obtidos em relação aos índices de geoprocessamento utilizados foi perceptível a variabilidade e da densidade da vegetação na área de estudo.

\section{REFERÊNCIAS}

ALSHAIKH, A. Y.. Space applications for droughtassessment in Wadi-Dama (West Tabouk), KSA.. The Egyptian Journal of Remote Sensing and Space Science, v.18, n.1, p.43-53, 2015.

AlbuQUeRQue, U. P.; ARAUJO, E. L.; El-DEIR, A. C. A.. Caatinga Revisited: ecology and Conservation of an Important Seasonal Dry Forest. The Scientific World Journal, v.2021, p.1-18, 2012.

CASTELLETTI, C. H. M.; SANTOS, A. M. M.; TABARELLI, M.; SILVA, J. M. C.. Quanto ainda resta da Caatinga? In: LEAL, I. R.; TABARELLI, M.; SILVA, J. M. C.. Uma estimativa preliminar: ecologia e conservação da caatinga. Recife: Editora Universitária, 2003, p.719-734.

CASTRO, A. S.; ARNÓBIO, C.. Flores da Caatinga. Campina Grande: INSA, 2011.

FERRAZ, A. S.; SOARES, V. P.; SOARES. C. P. B.; RIBEIRO, C. A. S. A; GLERIANI, J. M.. Uso de imagens do satélite IKONOS II para estimar biomassa aérea de um fragmento de floresta estacional semidecidual. IN: XVI SIMPÓSIO BRASILEIRO DE SENSORIAMENTO REMOTO - SBSR. Anais. Foz do Iguaçu,
2013.

IBGE. Instituto Brasileiro de Geografia e Estatística. Dados Shape File, 2019.

IBGE. Instituto Brasileiro de Geografia e Estatística. Manual técnico da vegetação brasileira. Rio de Janeiro, 1992.

PEREZ-MARIN, A. M.; SANTOS, A. P. S.. O semiárido brasileiro: riquezas, diversidades e saberes. Campina Grande: Instituto Nacional do Semiárido, 2014.

KIILL, L. H. P.; PORTO, D. D.. Bioma Caatinga: oportunidades e desafios de pesquisa para o desenvolvimento sustentável. In: VILELA, E. F.; CALLEGARO, G. M.; FERNANDES, G. W. (Org.). Biomas e agricultura: oportunidades e desafios. Rio de Janeiro: Academia Brasileira de Ciência, 2019.

LOURENÇO, V. R.; RAMOS, N. N. L. A.; COSTA, C. A. G.. Distribuição Espaço-Temporal do NDVI sob Condições de Caatinga Preservada. Espaço Aberto, PPGG - UFRJ, Rio de Janeiro. v, 7, n. 1, p.101-110, 2017. 
MITTERMEIER, R. A.; TURNER, W. R.; LARSEN, F. W.; BROOKS, T. M., GASCON, C. Global Biodiversity Conservation: The Critical Role of Hotspots. In: ZACHOS, F. E.; HABEL, J. C. Biodiversity Hotspots: distribution and Protection of Conservation Priority Areas. EditoraSpringer, 2011.

ONU. Organização das Nações Unidas. Transformando Nosso Mundo: a agenda 2030 para o Desenvolvimento Sustentável. ONU, 2015.

PEREIRA, J. D. A.; CAVALCANTI. A. K. G.; PIRES, A. L.; NETO. O. R.; CARVALHO. J. V. A.; SANTOS. L. C.; COELHO. M. S.; SOUSA. P. F. N.. A utilização de sensoriamento remoto para visualização de possíveis áreas desertificadas nos municípios de Cajazeiras e Coremas, PB. Brazilian Journal of Development, v.6, n.4, p.18009-18021, 2020.

PEREIRA, J. D. A.; NOGUEIRA, V. F. B.; NOGUEIRA, V. S.; CAVALCANTI, A. K. G.; PAIVA, F. J. S.. Análise dos impactos da seca no município de Sousa-PB. Revista Ibero-Americana de Ciências Ambientais, v.12, n.1, 2021.

ROUSE, J. W.; HAAS, R. H.; SCHELL, J. A.; DEERING, D. W. Monitoring vegetation systems in the great plains with ERTS. In: EARTH RESOURCES TECHNOLOGY SATELLITE SYMPOSIUM, 1. Annals. Washington, 1973.

TAVARES, V. C.. A percepção ambiental dos agricultores rurais do município de queimadas/PB sobre a degradação do
Bioma Caatinga. Revista ACTA Geográfica, v.12, n.28, p.7489,2018

TROVÃO, D. M.; SOUZA, B. C.; CARVALHO, E. C. D.; OLIVEIRA, P. T. B.; FERREIRA, L. M. R.. Espécies vegetais da caatinga associadas às comunidades de Abelhas (Hymenoptera: Apoidea: Apiformis). Revista Caatinga, v.22, n.3, p.136-143, 2009.

USGS. Serviço Geológico Norte Americano. Imagens digitais gratuitas do satélite LanSat 8, 2020.

SCARANO, F. R.; CEOTTO, P.. A importância da biodiversidade brasileira e os desafios para a conservação, para a ciência e para o setor privado. In: ROLIM, S. G.; MENEZES, L. F. T.; SRBEK-ARAUJO, A. C.. Floresta Atlântica de Tabuleiro: diversidade e endemismos na Reserva Natural Vale. Belo Horizonte, 2016.

SÁ, I. B.; RICHÉ, G. R; FOTIUS, G. A.. As paisagens e o processo de degradação do semiárido nordestino. In: SILVA, J. M. C., TABARELLI, M.; FONSECA, M. T.; LINS, L. V.. Biodiversidade da caatinga: áreas e ações prioritárias para a conservação, Brasília: MMA, 2003.

VELLOSO, A. L. E.; SAMPAIO, V. S. B.; PAREYN, F. G. C.. Ecorregiões: propostas para o Bioma caatinga. Recife: Instituto de Conservação Ambiental, 2002.

A CBPC - Companhia Brasileira de Produção Científica (CNPJ: 11.221.422/0001-03) detém os direitos materiais desta publicação. Os direitos referem-se à publicação do trabalho em qualquer parte do mundo, incluindo os direitos às renovações, expansões e disseminações da contribuição, bem como outros direitos subsidiários. Todos os trabalhos publicados eletronicamente poderão posteriormente ser publicados em coletâneas impressas sob coordenação da Sustenere Publishing, da Companhia Brasileira de Produção Científica e seus parceiros autorizados. Os (as) autores (as) preservam os direitos autorais, mas não têm permissão para a publicação da contribuição em outro meio, impresso ou digital, em português ou em tradução. 